Relations industrielles

Industrial Relations

\title{
Technical Change and Manpower Planning, by Salomon Barkin, O.C.D.E., Paris, 1967, 287 pp.
}

\section{Réjeanne Monette}

Volume 23, numéro 1, 1968

URI : https://id.erudit.org/iderudit/027884ar

DOI : https://doi.org/10.7202/027884ar

Aller au sommaire du numéro

Éditeur(s)

Département des relations industrielles de l'Université Laval

ISSN

0034-379X (imprimé)

1703-8138 (numérique)

Découvrir la revue

Citer ce compte rendu

Monette, R. (1968). Compte rendu de [Technical Change and Manpower Planning, by Salomon Barkin, O.C.D.E., Paris, 1967, 287 pp.] Relations industrielles / Industrial Relations, 23(1), 184-184.

https://doi.org/10.7202/027884ar

Tous droits réservés (C) Département des relations industrielles de l'Université Laval, 1968
Ce document est protégé par la loi sur le droit d'auteur. L'utilisation des services d'Érudit (y compris la reproduction) est assujettie à sa politique d'utilisation que vous pouvez consulter en ligne.

https://apropos.erudit.org/fr/usagers/politique-dutilisation/ 
générale », contient également quatre études. Celle qui porte sur la participation sociale au développement industriel met l'accent sur l'importance d'une collaboration entre les différents groupes sociaux, tout porticulièrement les employeurs, les travailleurs et leurs organisations, et de leur porticipation active ou processus d'industrialisotion, puis passe en revue les fins auxquelles cette participation serait utile et les formes qu'elle peut revêtir. Celle qui est consacrée ¿े «l'emploi et l'industrialisation » expose un certoin nombre de raisons pour lesquelles, à moins de mesures adéquates, le secteur industriel des poys en voie de développement emploie parfois moins de main-d'oeuvre que ne le justifierait la situation économique et sociale de ces régions. Elle examine ensuite diverses possibilités de créer dans l'industrie un plus grand nombre d'emplois opprofondie dans le document suivant, intitulé « Recherche d'une technologie progressive pour les pays en voie de développement s. Enfin, le document portant sur les salaires et le développement industriel relève que, lorsqu'un pays s'efforce de parvenir à l'industrialisation, le succès de celle-ci et lc manière dont les avantages du développement industriel seront réportis dépendront en partie du niveau des solaires, de leur structure et de leur taux d'accroissement. La même étude montre quelles difficultés se présentent dans ce domaine.

II est évident que c'est surtout oux pays intéressés qu'il oppartient de faire le nécessaire pour résoudre les problèmes posés par I'industrialisation dans le domaine social et en matière de main-d'oeuvre. Cependant, certaines formes d'action internationale peuvent contribuer à surmonter les difficultés. On a donc jugé approprié, dans des documents préparés d̀ l'intention d'un colloque international, $d^{\prime}$ accorder une attention porticulière aux possibilités d'exercer une action utile sur le plan international. Trois genres de mesures prises à cet échelon peuvent renforcer les politiques nationales en matière de main-d'oeuvre industrielle: a) fourniture de services consultatifs, de matériel et de personnel technique qualifié, dons le cadre de programmes de coopération technique, bilatéraux et multilatéroux; b) assistance financière; c) action commune des pays en voie de développement qui cnt des problèmes analogues. Les documents rassemblés ci-après contiennent diverses suggestions portant sur des mesures de ces trois catégories. En ce qui concerne plus particulièrement la première de ces possibilités d'action internationale, on $y$ trouvera quelques renseignements sur les moyens dont dispose I'O.I.T. et la contribution qu'elle peut appor- ter aux Etats Membres, sur leur demande, pour étudier les aspects des plans d'industrialisation qui touchent aux questions sociales et d̀ la main-d'oeuvre.

\section{Pierre DIONNE}

\section{Technical Change and Manpower Planning,} by Salomon Barkin, O.C.D.E., Paris, 1967, 287 pp.

Cette brochure, la $4 \mathrm{e}$ d'une série intitulée \& Industrial Relations Aspect of Manpower Policy », cherche d̀ définir les principes qui ont guidé les entreprises privées dans leurs politiques de main-d'beurre face ou changement technologique.

Le volume compte 29 études de cas faites dans huit pays différents. Le choix des cas a été fait par une équipe d'experts en vue d'offrir une gamme très variée de types de changements ò l'intérieur de différentes industries.

Chaque étude apporte un nouvel élément de réponse ò des questions telles que:

-Quel degré de coordination existe-t-il entre les prévisions de changements technologiques et les efforts fournis en vue d'ajustements de la main-d'oeuvre?

-Quelles méthodes a-t-on employées pour faire les prédictions en maind'oeuvre et comment a-t-orı ajusté ces besoins à la force existante?

-A quel moment a-t-on eu recours à la consultation? $Y$ a-t-il eu riégociation?

-Quels ont été les avantages tirés du changement technique? Pour l'employeur? Pour l'employé?

Plus qu'une simple description, on cherche à montrer comment on a pu ou dans quelques cas comment on pourrait intégrer ces mesures individuelles à une politique de maind'oeuvre plus globale voir nationale. Cependant chaque cas demeure spécifique et ce n'est pas parce qu'une expérience a été profitable à une entreprise qu'on peut l'adopter comme une règle. II reste que ces études peuvent apporter un supplément aux politiques gouvernementales. La brochure prouve qu'une co-ordination des programmes est possible en vue d'établir une véritable politique de main-d'oeuvre où chacun (patronat, corps public, syndicat) a une meilleure compréhension de son rôle et de ses responsabilités.

Réjeonne MONETTE 